\title{
Unaccustomed exercise causes rhabdomyolysis
}

\section{Not one type rhabdomyolysis... exercise does

\author{
of exercise causes \\ any unaccustomed
}

Cross Fit ${ }^{\mathrm{TM}}$ is a relatively new strength and conditioning program defined as "constantly varied, functional movements, performed at a high intensity". The goal of the program is to increase "work capacity across broad time and modal domains". ${ }^{1}$ Even though this training modality has been criticized by the main stream media for "high risk of injury" most of these claims have been anecdotal, as recent evidence suggest this training modality is not any more "dangerous" than other exercise programs. ${ }^{2}$ One of the biggest criticisms of this training modality has been its association with Rhabdomyolysis, a condition that results in the breakdown of muscle tissue and can result in death $[3,4]$. However, these claims have not been substantiated by any study looking at the incidence of injury due to Cross Fit participation. ${ }^{2,5,6}$

\section{CrossFit ${ }^{\circledR}$ causes rhabdomyolysis}

The premise that Cross Fit ${ }^{\mathrm{TM}}$ causes Rhabdomyolysis suggests a "cause and effect" that has simply not been reported before and it is based on the experience of single individuals, which is far from the number required to make this type of association. Of course, it is unfortunate that anyone would experience an injury due to his or her participation in any type of physical activity. The development of Rhabdomyolysis due to exercise it is possible, but so is sudden cardiac death during an athletic event ${ }^{7}$ or during an exercise stress test. ${ }^{8}$ The risk of injury, and or death, is inherent to any type of physical activity. Nonetheless, we continue to promote physical activity and exercise to people around the world because the benefits of such activity outweigh the risks for most individuals. The U.S. Department of Health and Human Services encourages all individuals to engage in physical activity of low, moderate or vigorous intensity, suggesting that being sedentary is more "dangerous" than participating in any type of activity. ${ }^{9}$

\section{Rhabdomyolysis in the scientific literature}

If we look to the scientific literature to guide our understanding of this condition, we find several instances where Rhabdomyolysis has occurred as a result of some type of physical activity (exertional Rhabdomyolysis). Inklebarger and colleagues ${ }^{10}$ reported the first case of self-induced exertional Rhabdomyolysis in a 63-year-old woman who exercised on a stationary bike a day prior to her emergency room visit. In 2011, Boni and Rabiti ${ }^{11}$ reported a case of exertional Rhabdomyolysis after a session of indoor cycling and three other cases have been reported specifically related to resistance training, all of which occurred in a national fitness center chain. ${ }^{12,13}$ However, exertional Rhabdomyolysis has also been reported in young adults while performing "less strenuous" activities. A 25-year-old woman required hemodialysis for six-weeks after hiking for hours in the Grand Canyon ${ }^{14}$ A 19 -year-old college freshman experience exertional Rhabdomyolysis after playing in an ultimate Frisbee tournament. ${ }^{15}$ Therefore, to say that Cross Fit ${ }^{\mathrm{TM}}$ causes Rhabdomyolysis is like blaming your favorite running shoe $<<$ ENTER BRAND NAME HERE $>>$ for your shin splints.

\author{
Volume I Issue 2 - 2014
}

\begin{abstract}
Yuri Feito
Department of Exercise Science and Sport Management, USA

Correspondence: Yuri Feito, Assistant Professor, Department of Exercise Science \& Sport Management, Kennesaw State University, 520 Parliament Garden Way NW, MD 4I 04, BIdg. 4I, Office 4018, GA 30144, Kennesaw, USA, Tel 4705787764, Fax 770420446I,Email yfeito@kennesaw.edu
\end{abstract}

Received: October 3I, 2014 | Published: November I, 2014

Exertional Rhabdomyolysis is caused by a breakdown of muscle fibers due to unaccustomed exercise and it is a life-threatening condition, characterized by muscular pain, muscle weakness, and dark urine. Seeking early treatment is paramount to minimize damage to the kidneys and preventing kidney failure. Even though overexertion may be a significant factor leading to this condition, other factors including dehydration, heat stress, nutritional supplementation, drug use, bacterial or viral infections, genetic conditions (e.g. sickle cell trait), or metabolic defects in the muscle may exacerbate muscle damage, regardless of the exercising intensity. ${ }^{13}$ Therefore, individuals, coaches and fitness professionals should be aware of these factors to minimize the risk of this condition regardless of the training modality being performed.

\section{Acknowledgments}

None.

\section{Conflicts of interest}

The author declares that there is no conflict of interes.

\section{References}

1. Glassman G. Understanding CrossFit. CrossFit Journal. 2007;56: p. $1-2$.

2. Hak PT, Hodzovic E, Hickey B. The nature and prevalence of injury during CrossFit training. J Strength Cond Res. 2013.

3. Zimmerman JL, Shen MC. Rhabdomyolysis. Chest. 2013;144(3):10581065 .

4. Sayers SP, Clarkson PM. Exercise-induced rhabdomyolysis. Curr Sports Med Rep. 2002;1(2):59-60.

5. Weisenthal BM. Injury Rate and Patterns Among CrossFit Athletes. The Orthopaedic Journal of Sports Medicine. 2014;2(4).

6. Feito Y, A Paul. Prevalence of Injury Among CrossFitTM Participants. Medicine \& Science in Sports \& Exercise, 2014;46(5S):759-769.

7. Koester MC. A Review of Sudden Cardiac Death in Young Athletes and Strategies for Preparticipation Cardiovascular Screening. J Athl Train. 2001;36(2):197-204.

8. Morise AP. Exercise testing in nonatherosclerotic heart disease: hypertrophic cardiomyopathy, valvular heart disease, and arrhythmias. Circulation. 2011;123(2):216-225. 
9. Physical Activity Guidelines for Americans. 2008: p. 1-65.

10. Inklebarger, Galanis N, Kirkos J, et al. Exercise-induced rhabdomyolysis from stationary biking: a case report. Hippokratia. 2010;14(4):279-80.

11. Boni R, Rabitti PG. Spinning-induced rhabdomyolysis: importance of MRI for patient's outcome a case report. Reumatismo. 2011;63(1):44-48.

12. Casares P, Marull J. Over a millon Creatine Kinase due to a heavy workout: A case report. Cases J. 2008;1(1):173.
13. Springer BL, PM Clarkson. Two cases of exertional rhabdomyolysis precipitated by personal trainers. Med Sci Sports Exerc. 2003; 35(9):1499-1502.

14. Clarkson PM. Worst Case Scenarios: Exertional Rhabdomyolysis and Acute Renal Failure, in Sports Science Exchange,1993.

15. Krivickas LS. Recurrent rhabdomyolysis in a collegiate athlete: a case report. Med Sci Sports Exerc. 2006;38(3):407-410. 